\title{
The transcriptional landscape of CTEC and mTEChi.
}

\author{
Shahan Mamoor ${ }^{1}$ \\ 1Thomas Jefferson School of Law \\ San Diego, CA 92901 \\ mamoorsk@tjsl.edu
}

The thymus is the site of positive and negative selection, the processes by which lymphocytes are selected for that are capable, in their T-cell receptors, of adequately recognizing foreign antigen, and selected against in the event that, by their T-cell receptors, they recognize self antigen (1-16). It is anatomically segregated into a medulla and cortex, and epithelial cells in both the medulla and cortex function in the processes of negative and positive selection but there are limited studies assessing in an unbiased, systematic manner their relative basic transcriptional natures (17-26). In this study we compared the transcriptomes of cortical epithelial cells (cTEC) and medullary epithelial cells expressing high levels of the class II major histocompatibility complex (MHC-II) (mTEChi) (27). We previously described the major transcription factors and epigenetic machinery that uniquely describe cTEC and mTEChi (28). Here, using a published dataset, we report a series of modules consisting of cell surface receptors, Fbox proteins, proteasomal components, cytochrome P450 components, ATP-related machinery of the lysosome and mitochondria, and matrix metalloproteinases that, by their differential expression, uniquely describe cTEC and mTEChi. These data will serve as a resource for future efforts towards molecular engineering of the thymus for transplant medicine and targeted treatment of autoimmunity.

Keywords: thymus, medulla, cortex, medullary epithelial cells, cortical epithelial cells, mTEC, cTEC, transcriptome analysis of the immunologically active cells of the thymus, systems analysis of the thymus, positive selection, negative selection. 


\section{Introduction}

The ability to discern what is self and what is foreign is essential for the immune system to be able to adequately protect the human body from pathogens and at the same time to prevent "friendly fire", or the recognition of the thousands of self antigens the body possesses as foreign (1-16). The site at which this ability is developed is known as the thymus, an organ in the chest of every human. The thymus possesses a thymus and medulla $(3,4)$, and epithelial cells in the cortex of the thymus (cTEC) participate in positive selection $(1,2,8-13,15)$, the process by which lymphocytes expressing T-cell receptors that possess an optimal binding affinity for MHC-peptide receptor complexes are selected for, while epithelial cells in the medulla of the thymus (mTEChi) participate in negative selection, the process by which lymphocytes that express T-cell receptors that have the potential to recognize self-antigen in complex with MHC-II are deleted so as to prevent autoimmune reactions $(1,2,5,7,14)$.

The general transcriptional behavior of TTEChi $^{\text {i }}$ and cTEC have been explored to some extent (17-26), but there are limited unbiased, systematic analyses of their transcriptional landscapes: how they relate to each other, and how they most differ from each other. In this study, we performed global differential gene expression analysis by comparing the transcriptomes of mTEChi and CTEC isolated from the murine thymus using a published dataset (27). We found a discrete gene expression program consisting of modules that uniquely identified the mTEChi and cTEC lineages. This program included Fbox genes with opposing expression in either lineage, multiple proteasomal genes, centromere proteins, cell surface receptors, major histocompatibility complex genes, ATP-related genes, matrix metalloproteinases, cell 
cycle genes and others. These data will serve as a resource for future efforts aimed at engineering the thymus for novel therapeutics aimed at curbing transplant rejection and autoimmune responses across tissues.

\section{Methods}

GSE89965 (27) was utilized for this differential gene expression analysis, performed using GEO2R. This public dataset was generated by Jakub Abramson using microarray (Affymetrix Mouse Gene 1-ST array) analysis of Aire-GFP, EpCAM+Ly51+ cells (cTEC), Aire-GFP Epcam+MHC-II(hi) cells (mTEChi); $n=4$ from mTEChi; $n=3$ from cTEC, from C57BI/6 Adig mice 6 weeks of age (adult). No adjustment was made to $p$-values, and there was no log-transformation applied to the data. The NCBI generated category of platform annotation was used. An unpaired two-tailed t-test with Welch's correction was utilized to determine the statistical significance of the RNA expression values between each cell type.

\section{Results}

We performed global gene expression profiling of medullary and cortical epithelial cells isolated from the murine thymus (27) to systematically compare the transcriptomes of cells participating in negative and positive selection. Using this analysis, we identified the most significant differences in the transcriptional landscapes of the mammalian mTEChi and cTEC. 
Fbxl15 and Fbxl17 expression uniquely define the mTEChi and cTEC lineages

Fbxl15, F-box and leucine-rich repeat protein 15, was the 9th most differentially expressed gene when comparing the mTEChi and cTEC transcriptomes (Table 1; $\mathrm{p}=4.9 \mathrm{E}-07$ ), while Fbxl17, F-box and leucine-rich repeat protein 17 was the $62 \mathrm{nd}$ most differentially expressed gene when comparing the mTEChi and cTEC transcriptomes (Table 1; $p=5.11 \mathrm{E}-06$ ).

Fbxl15 and Fbxl17 expression opposed each other, with higher expression of Fbxl15 in cTEC (Figure 1; $p=0.0012$ ) and higher expression of Fbxl17 in mTEChi (Figure $1 ; p<0.0001)$.

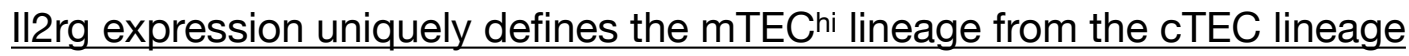

The gamma chain of the interleukin 2 receptor, II2rg, was the 46th most differentially expressed gene when comparing the mTEChi and cTEC transcriptomes (Table 1; $p=3.5 E-06$ ). Expression of $I I 2 r g$ was significantly higher in $\mathrm{mTEC}^{\text {hi }}$ than in cTEC (Figure 2; $p=0.0003$ ).

Scarf2, Csf2ra, Tnfrsf11a, Skint7 expression uniquely define the mTEChi and cTEC lineages.

Scarf2, scavenger receptor class $F$, member 2 , was the 53rd most differentially expressed gene when comparing the mTEChi and CTEC transcriptomes (Table 1; $\mathrm{p}=4.26 \mathrm{E}-06$ ). Expression of Scarf2 was significantly higher in cTEC than in mTEChi (Figure 3; $p=0.0030$ ).

Csf2ra, colony stimulating factor 2 receptor, alpha, low-affinity (granulocytemacrophage), was the 110th most differentially expressed gene when comparing the 
mTEChi $^{\text {hi }}$ and CTEC transcriptomes (Table 1; $\mathrm{p}=1.01 \mathrm{E}-05$ ). Expression of Csf2ra was significantly higher in cTEC than in mTEChi (Figure 3; $p<0.0001$ ).

Tnfrsf11a, tumor necrosis factor receptor superfamily, member 11a, NFKB activator, was the 224th most differentially expressed gene when comparing the

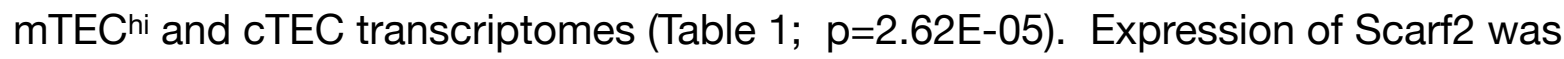
significantly higher in $\mathrm{mTEC}^{\text {hi }}$ than in CTEC (Figure 3; $p=0.0002$ ).

Skint7, selection and upkeep of intraepithelial T cells 7, was the 9th most differentially expressed gene when comparing the mTEChi and cTEC transcriptomes (Table 1; $\mathrm{p}=4.99 \mathrm{E}-06$ ). Expression of Skint7 was significantly higher in mTEChi than in cTEC (Figure 3; $p=0.0016$ ).

Bmp8a and Wnt4 expression uniquely define the cTEC lineage from the mTEChi lineage.

Bmp8a, bone morphogenetic protein 8a, was the 65th most differentially expressed gene when comparing the mTEChi and cTEC transcriptomes (Table 1; $p=5.29 E-06)$. Expression of Bmp8a was significantly higher in CTEC than in mTEChi (Figure 4; $p<0.0001$ ).

Wnt4, wingless-type MMTV integration site family, member 4, was the 36th most differentially expressed gene when comparing the mTEChi and cTEC transcriptomes (Table 1; $\mathrm{p}=2.6 \mathrm{E}-06$ ). Expression of Wnt4 was significantly higher in cTEC than in

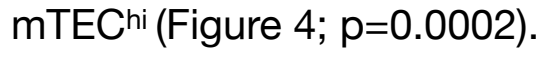

Psme1, Psma6 and Psmd6 expression uniquely define the mTEChi lineage from the cTEC lineage. 
Psme1, proteasome (prosome, macropain) activator subunit 1 (PA28 alpha), was the 41st most differentially expressed gene when comparing the mTEChi and cTEC transcriptomes (Table 1; $\mathrm{p}=3.21 \mathrm{E}-06$ ). Expression of Psme1 was significantly higher

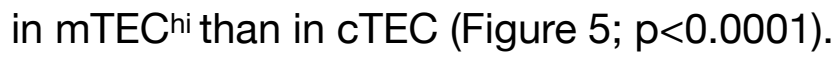

Psmd6, proteasome (prosome, macropain) 26S subunit, non-ATPase, 6, was the 155th most differentially expressed gene when comparing the mTEChi and CTEC transcriptomes (Table 1; $\mathrm{p}=1.55 \mathrm{E}-05$ ). Expression of Psma6 was significantly higher in

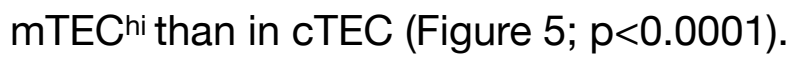

Psma6, proteasome (prosome, macropain) subunit, alpha type 6, was the 187th most differentially expressed gene when comparing the mTEChi and CTEC transcriptomes (Table 1; $\mathrm{p}=2 \mathrm{E}-05$ ). Expression of Psmd6 was significantly higher in

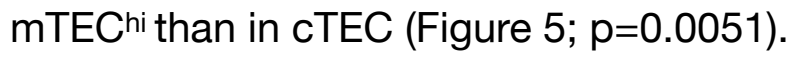

Cep350 and Cep162 expression uniquely define the mTEChi lineage from the cTEC lineage

Cep350, centrosomal protein 350 , was the 98th most differentially expressed gene when comparing the mTEChi and cTEC transcriptomes (Table 1; $\mathrm{p}=8.91 \mathrm{E}-06$ ). Expression of Cep350 was significantly higher in mTEChi than in cTEC (Figure 6; $\mathrm{p}<0.0001)$

Cep162, centrosomal protein 162, was the 48th most differentially expressed gene when comparing the mTEChi and cTEC transcriptomes (Table 1; $p=3.63 E-06$ ). Expression of Cep162 was significantly higher in mTEChi than in cTEC (Figure 6; $\mathrm{p}<0.0001)$ 
A (Nonagouti) expression uniquely defines the cTEC lineage from the mTEChi lineage.

A (nonagouti), was the 78th most differentially expressed gene when comparing the $\mathrm{mTEC}^{\text {hi }}$ and cTEC transcriptomes (Table 1; $\mathrm{p}=6.53 \mathrm{E}-06$ ). Expression of $\mathrm{A}$ (nonagouti) was significantly higher in cTEC than in mTEChi (Figure $7 ; p<0.0001$ ).

Cyp4f39, Cyp1a2, and Cyp2w1 expression uniquely define the mTEChi and cTEC lineages.

Cyp1a2, cytochrome P450, family 1 , subfamily a, polypeptide 2 , was the 45 th most differentially expressed gene when comparing the mTEChi and cTEC transcriptomes (Table 1; $\mathrm{p}=3.49 \mathrm{E}-06$ ). Expression of Cyp1a2 was significantly higher in mTEChi than in cTEC (Figure 8; $p=0.0002$ ).

Cyp2w1, cytochrome P450, family 2, subfamily w, polypeptide 1 , was the 138th most differentially expressed gene when comparing the mTEChi and cTEC transcriptomes (Table 1; $\mathrm{p}=1.31 \mathrm{E}-05)$. Expression of Cyp2w1 was significantly higher in CTEC than in mTEChi (Figure 8; $p<0.0001$ ).

Cyp4f39, cytochrome P450, family 4, subfamily f, polypeptide 39 , was the $173 \mathrm{rd}$ most differentially expressed gene when comparing the mTEChi and CTEC transcriptomes (Table 1; $\mathrm{p}=1.84 \mathrm{E}-05$ ). Expression of Cyp4f39 was significantly higher

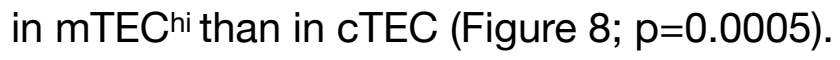

Atp6v1b2, Atp6v01a, and Atp5f1 expression uniquely define the mTEChi lineage from the cTEC lineage.

Atp5f1, ATP synthase, $\mathrm{H}+$ transporting, mitochondrial F0 complex, subunit B1, was the 135th most differentially expressed gene when comparing the mTEChi and 
cTEC transcriptomes (Table 1; $p=1.27 \mathrm{E}-05$ ). Expression of Atp5f1 was significantly higher in mTEChi than in cTEC (Figure 9; $p<0.0001)$.

Atp6v1b2, ATPase, $\mathrm{H}+$ transporting, lysosomal V1 subunit B2, was the 167th most differentially expressed gene when comparing the MTEC $^{\text {hi }}$ and CTEC transcriptomes (Table 1; $\mathrm{p}=1.71 \mathrm{E}-05$ ). Expression of Atp6v1b2 was significantly higher

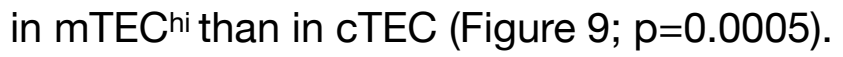

Atp6v01a, ATPase, $\mathrm{H}+$ transporting, lysosomal V0 subunit A1, was the 169th most differentially expressed gene when comparing the mTEChi and cTEC transcriptomes (Table 1; $\mathrm{p}=1.76 \mathrm{E}-05)$. Expression of Atp6v01a was significantly higher

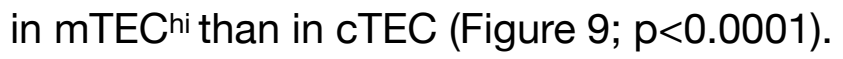

Dock6 and Dock 10 expression uniquely define the mTEChi lineage from the cTEC lineage.

Dock10, dedicator of cytokinesis 10 , was the 121 st most differentially expressed gene when comparing the mTEChi and CTEC transcriptomes (Table 1; $p=1.11 \mathrm{E}-05$ ). Expression of Dock10 was significantly higher in mTEChi than in cTEC (Figure 10; $\mathrm{p}=0.0005)$.

Dock6, dedicator of cytokinesis 6 , was the 246th most differentially expressed gene when comparing the mTEChi and cTEC transcriptomes (Table 1; $\mathrm{p}=2.98 \mathrm{E}-05$ ). Expression of Dock6 was significantly higher in mTEChi than in cTEC (Figure 10; $\mathrm{p}=0.0002)$. 
Vps13a and Vps13d expression uniquely define the mTEChi lineage from the cTEC lineage.

Vps13a, vacuolar protein sorting 13A, was the 52nd most differentially expressed gene when comparing the mTEChi and cTEC transcriptomes (Table 1; $\mathrm{p}=4.04 \mathrm{E}-06$ ). Expression of Vps13a was significantly higher in mTEChi than in cTEC (Figure 11; $p<0.0001)$.

Vps13d, vacuolar protein sorting 13D, was the 232nd most differentially expressed gene when comparing the mTEChi and CTEC transcriptomes (Table 1; $\mathrm{p}=2.75 \mathrm{E}-05)$. Expression of Vps13d was significantly higher in mTEChi than in cTEC (Figure 11; $p=0.0002$ ).

$\mathrm{H} 2-\mathrm{Ab} 1, \mathrm{H} 2-\mathrm{DMb} 2, \mathrm{H} 2-\mathrm{T} 22$ and $\mathrm{H} 2-\mathrm{Aa}$ expression uniquely define the mTEChi lineage from the cTEC lineage.

$\mathrm{H}$ 2-Aa, histocompatibility 2, class II antigen A, alpha, was the 22nd most differentially expressed gene when comparing the mTEChi and cTEC transcriptomes (Table 1; $\mathrm{p}=1.34 \mathrm{E}-06$ ). Expression of $\mathrm{H} 2-\mathrm{Aa}$ was significantly higher in $\mathrm{mTEC}^{\mathrm{hi}}$ than in cTEC (Figure 12; $p=0.0004)$.

$\mathrm{H} 2-\mathrm{Ab} 1$, histocompatibility 2, class II antigen A, beta 1, was the 154th most differentially expressed gene when comparing the mTEChi and cTEC transcriptomes (Table 1; $\mathrm{p}=1.54 \mathrm{E}-05$ ). Expression of $\mathrm{H} 2-\mathrm{Ab} 1$ was significantly higher in mTEChi than in cTEC (Figure 12; $p=0.0017$ ).

H2-DMb2, histocompatibility 2, class II, locus Mb2, was the 234rd most differentially expressed gene when comparing the mTEChi and CTEC transcriptomes (Table 1; $\mathrm{p}=2.76 \mathrm{E}-05)$. Expression of $\mathrm{H} 2-\mathrm{DMb} 2$ was significantly higher in mTEChi than in cTEC (Figure 12; $p=0.0001$ ). 
H2-T22, histocompatibility $2, \mathrm{~T}$ region locus 22 , was the 213th most differentially expressed gene when comparing the mTEChi and cTEC transcriptomes (Table 1; $\mathrm{p}=2.51 \mathrm{E}-05)$. Expression of $\mathrm{H} 2-\mathrm{T} 22$ was significantly higher in mTEChi than in cTEC (Figure 12; $p=0.0004)$.

Adam8 and Adam23 expression uniquely define the mTEChi lineage from the CTEC lineage.

Adam8, a disintegrin and metallopeptidase domain 8, was the 147th most differentially expressed gene when comparing the mTEChi and cTEC transcriptomes (Table 1; $\mathrm{p}=1.39 \mathrm{E}-05$ ). Expression of Adam8 was significantly higher in mTEChi than in CTEC (Figure 13; $p=0.0007$ ).

Adam23, a disintegrin and metallopeptidase domain 23, was the 199th most differentially expressed gene when comparing the mTEChi and cTEC transcriptomes (Table 1; $p=2.25 E-05)$. Expression of Adam23 was significantly higher in mTEChi than in cTEC (Figure 13; $p=0.0003$ ).

Cdca5 and Anapc2 expression uniquely define the MTEChi lineage and CTEC lineages.

Cdca5, cell division cycle associated 5 , was the 183 rd most differentially expressed gene when comparing the mTEChi and CTEC transcriptomes (Table 1; $\mathrm{p}=1.98 \mathrm{E}-05$ ). Expression of Cdca5 was significantly higher in cTEC than in mTEChi (Figure 14; $p<0.0001)$.

Anapc2, anaphase promoting complex subunit 2, was the 127th most differentially expressed gene when comparing the mTEChi and CTEC transcriptomes (Table 1; $\mathrm{p}=1.18 \mathrm{E}-05$ ). Expression of Anapc2 was significantly higher in mTEChi than in cTEC (Figure 14; $p=0.0005)$. 


\section{Discussion}

In this study we compared the transcriptomes of epithelial cells from the cortex (cTEC) and medulla of the thymus (27); specifically, medullary epithelial cells expressing high levels of the peptide antigen receptor MHC-II (mTEChi) to understand in an unbiased, systematic fashion the major transcriptional differences between these two cell types that participate in the critical immunological processed of positive and negative selection. We found a discrete gene expression program organized into modules consisting of Fbox genes, proteasome components, ATP-related proteins of the lysosome and mitochondria, matrix metalloproteinases, major histocompatibility genes, genes involved in trafficking of cellular cargoes including vacuolar sorting proteins and Dock proteins, cytochrome oxidases, centromere proteins as well as cell surface receptors whose differential expression uniquely defined the mTEChi and CTEC lineages.

We previously described a set of epigenetic proteins and transcription factors whose expression uniquely define the mTEChi and cTEC lineages (28). We are the first to report that opposite expression of Fbox genes Fbxl15 and Fbxl17 mark the cTEC and mTEChi lineages, respectively. The function of these genes in cTEC and mTEChi remains to be discerned but analysis of their function in either cell type in vivo requires the development of more specific Cre-lox drivers than Foxn1 and $\beta 5 t$ as either of these would mark both cTEC and mTEChi.

One study assessed the level of Psma6 in mTEChi but did not distinguish between CTEC and mTEChi in that study and instead measured Psma6 expression by 
flow cytometry in the mTEChi of mice that were doubly deficient in immunoproteasome components Psmb8 and Psmb10 (29).

Unique expression of centromere proteins Cep162 and Cep350 has not previously been reported.

One study has previously reported that Bmp8a could only be detected in spleen, testis, and brain (30). We found here that expression of Bmp8a not only could be detected in the thymus but its differential expression marked cells of the cortex of the thymus. Another study that analyzed expression of Bmp family genes in the thymus of Aire knockout mice found that, unlike other Bmp family genes, the expression of Bmp8a was not different between Aire-/- and Aire wild-type mice but did not assess the expression of Bmp8a in cTEC and mTEChi (31).

Wnt4 expression in the thymus has been widely reported $(32,33)$ and it is thought to regulate cellularity in the thymus (34) as well as, in a more artificial setting, protect cells of the thymus against dexamethasone-induced senescence (35). Wnt4 expression in the thymus is reported to decrease upon aging (36). Transduction of fetal thymocytes in vitro with Wnt4 results in enhanced survival (32). Deletion of Wnt4 in mice results in a $20-30 \%$ decrease in thymocytes in the fetal thymus at E15-16 (34). We also previously reported that Wnt4 expression is higher in mTEClo than in mTEChi (37), thus establishing a Wnt4 expression gradient in the thymus, of highest Wnt4 expression in mTEClo, then in mTEChi, and lowest Wnt4 expression in cTEC.

Nude mice are a type of immunodeficient mutant mouse that are athymic due to a mutation in the gamma chain of the IL-2 receptor, II2rg (38). We found that while mTEChi express relatively high levels of II2rg, cTEC expression virtually no II2rg. Thus, 
while cTEC essentially lack expression of II2rg, II2rg is essential for the development of cells of the thymus including cTEC.

Skint7 is poorly characterized. Skint1 is a specific marker for $V_{y} 5 \mathrm{~V} \delta 1+$ dendritic epidermal T-cells (39). Skint7 shares $83 \%$ homology with Skint8 which was recently shown to negatively regulate T-cell responses in vitro and share sequence homology to the B7 family of co-stimulatory molecules (40). We found that differential Skint7 expression marks the mTEChi lineage.

Tnfrsf11a, or RANK (receptor activator of NFkB signaling) expression in the thymus has previously been reported (41).

Together with previous findings (37), we demonstrate a graded expression of Scarf2 in the thymus, with highest expression in the cortex, then lower expression in mTEClo, and the lowest relative expression in mTEChi.

A (non agouti) expression has not been previously demonstrated in the thymus.

Cyp4f39 expression in the thymus has been reported but not specifically in mTEC or CTEC (42). There has been no functional assignment for this cytochrome protein in cells of the thymus.

We previously reported that Cyp1a2 expression is also relatively very low in the mTEClo (37). Thus, Cyp1a2 expression uniquely marks mTEChi from mTEClo and cTEC.

The expression of Cyp2w1 expression in cTEC has not previously been reported. Interestingly, Cyp2w1 is cited as a biomarker for cancers and its expression is thought to be highest in adrenal glands (43-45).

Atp6v1b2 is a high confidence Foxn1 target gene, supporting our finding that it is differentially expressed in cells of the thymus (46). Recurrent de novo misense 
mutations of Atp6v1b2 have been found in Zimmerman-Laband Syndrome, a rare genetic disorder featuring craniofacial abnormalities and children with extremely large gums (47).

There is essentially no literature describing any role for Atp6v01a. Atp5f1 expression in the thymus has also not been previously reported.

Dock6 expression has been reported in the epithelium of the thymus in the context of interaction with the Mob1 protein (48). Dock10 has also been reported to be expressed in the thymus $(51,52)$.

Vps13a has been reported broadly in the thymus but not specifically in mTEC or cTEC (49). Vps13d has been reported as a peptide that eluted from MHC-I complexes and belonging to set of genes possessing a "high thymic Z score" and having expression almost exclusively in hematolymphoid organs (50). A specific function for this cellular transport module in mTEChi has not been established.

$\mathrm{H} 2-\mathrm{Ab} 1$ is a class II MHC molecule and its expression has been reported in the medullary epithelial cells of the thymus; $\mathrm{H} 2-\mathrm{Aa}$ expression has also been reported in mTEC (5) . H2-Dmb2 expression has been reported in the thymus, specifically in mTECs, and its expression is dependent on the Class II transcriptional activator CIITA (5). A study of gamma delta T-cells ablated the entire $\mathrm{H} 2-\mathrm{T}$ locus and found no deficits in T-cell development in the thymus (54).

Adam8 is expressed in the thymic stroma and deficiency in Adam8 leads to hypercellularity in the thymus (55). Adam23 has been reported to possess highest expression in the brain (56), but we could not find locate any literature describing differential expression of Adam23 in mTEC and cTEC. 
With respect to the cell cycle module identified here, Cdca5 expression has been reported in an mTEC cell line but its expression in the medulla or cortex of the mammalian thymus has not specifically been described (57). Anapc2 expression has been reported in the thymus but not differentially in mTEChi and cTEC (58).

In conclusion, we demonstrate the existence of several key modules that differentially mark the mTEChi and CTEC lineages by their relative expression, consisting of transcripts produced by Fbox genes, proteasome genes, genes encoding multiple cell surface receptors, centromere proteins, Adam-family matrix metalloproteinases, ATP-related machinery of the lysosome and mitochondria, cellular transport proteins of the Dock and VPS families, as well as cell cycle proteins. The molecular descriptions provided in this study, by comparing the transcriptomes of mTEChi and CTEC, will serve as a resource for the specific and targeted engineering of the epithelial cells of the thymus for the treatment of transplant rejection and for the reestablishment of tolerance in autoimmune maladies across tissues. 


\section{References}

1. Surh, C.D. and Sprent, J., 1994. T-cell apoptosis detected in situ during positive and negative selection in the thymus. Nature, 372(6501), p.100.

2. Blackman, M., Kappler, J. and Marrack, P., 1990. The role of the T cell receptor in positive and negative selection of developing T cells. Science, 248(4961), pp. $1335-1341$.

3. Rodewald, Hans-Reimer, Sabine Paul, Corinne Haller, Horst Bluethmann, and Carmen Blum. "Thymus medulla consisting of epithelial islets each derived from a single progenitor." Nature 414, no. 6865 (2001): 763.

4. Rossi, S.W., Jenkinson, W.E., Anderson, G. and Jenkinson, E.J., 2006. Clonal analysis reveals a common progenitor for thymic cortical and medullary epithelium. Nature, 441 (7096), p.988.

5. Hinterberger, M., Aichinger, M., Da Costa, O.P., Voehringer, D., Hoffmann, R. and Klein, L., 2010. Autonomous role of medullary thymic epithelial cells in central CD4+ T cell tolerance. Nature immunology, 11(6), p.512.

6. Anderson, M.S., Venanzi, E.S., Klein, L., Chen, Z., Berzins, S.P., Turley, S.J., Von Boehmer, H., Bronson, R., Dierich, A., Benoist, C. and Mathis, D., 2002. Projection of an immunological self shadow within the thymus by the aire protein. Science, 298(5597), pp.1395-1401.

7. Liston, A., Lesage, S., Wilson, J., Peltonen, L. and Goodnow, C.C., 2003. Aire regulates negative selection of organ-specific T cells. Nature immunology, 4(4), p. 350.

8. Laufer, T.M., DeKoning, J., Markowitz, J.S., Lo, D. and Glimcher, L.H., 1996. Unopposed positive selection and autoreactivity in mice expressing class II MHC only on thymic cortex. Nature, 383(6595), p.81.

9. Bill, J. and Palmer, E., 1989. Positive selection of CD4+ T cells mediated by MHC class II-bearing stromal cell in the thymic cortex. Nature, 341(6243), p.649.

10. Moran, A.E. and Hogquist, K.A., 2012. T-cell receptor affinity in thymic development. Immunology, 135(4), pp.261-267.

11. Klein, L., Hinterberger, M., Wirnsberger, G. and Kyewski, B., 2009. Antigen presentation in the thymus for positive selection and central tolerance induction. Nature Reviews Immunology, 9(12), p.833. 
12. Stefanski, H.E., Mayerova, D., Jameson, S.C. and Hogquist, K.A., 2001. A low affinity TCR ligand restores positive selection of CD8+ T cells in vivo. The Journal of Immunology, 166(11), pp.6602-6607.

13. von Boehmer, H., 1994. Positive selection of lymphocytes. Cell, 76(2), pp.219-228.

14.Palmer, E., 2003. Cell death and immunity: Negative selection-clearing out the bad apples from the T-cell repertoire. Nature Reviews Immunology, 3(5), p.383.

15. Kretz-Rommel, A. and Rubin, R.L., 2000. Disruption of positive selection of thymocytes causes autoimmunity. Nature medicine, 6(3), p.298.

16. Aichinger, M., Wu, C., Nedjic, J. and Klein, L., 2013. Macroautophagy substrates are loaded onto $\mathrm{MHC}$ class II of medullary thymic epithelial cells for central tolerance. Journal of Experimental Medicine, 210(2), pp.287-300.

17. Chuprin, A., Avin, A., Goldfarb, Y., Herzig, Y., Levi, B., Jacob, A., Sela, A., Katz, S., Grossman, M., Guyon, C. and Rathaus, M., 2015. The deacetylase Sirt1 is an essential regulator of Aire-mediated induction of central immunological tolerance. Nature immunology, 16(7), p.737.

18. Herzig, Y., Nevo, S., Bornstein, C., Brezis, M.R., Ben-Hur, S., Shkedy, A., Eisenberg-Bord, M., Levi, B., Delacher, M., Goldfarb, Y. and David, E., 2017. Transcriptional programs that control expression of the autoimmune regulator gene Aire. Nature immunology, 18(2), p.161.

19. Miragaia, R.J., Zhang, X., Gomes, T., Svensson, V., llicic, T., Henriksson, J., Kar, G. and Lönnberg, T., 2018. Single-cell RNA-sequencing resolves self-antigen expression during mTEC development. Scientific reports, 8(1), p.685.

20. Brennecke, P., Reyes, A., Pinto, S., Rattay, K., Nguyen, M., Küchler, R., Huber, W., Kyewski, B. and Steinmetz, L.M., 2015. Single-cell transcriptome analysis reveals coordinated ectopic gene-expression patterns in medullary thymic epithelial cells. Nature immunology, 16(9), p.933.

21. Ki, S., Park, D., Selden, H.J., Seita, J., Chung, H., Kim, J., Iyer, V.R. and Ehrlich, L.I., 2014. Global transcriptional profiling reveals distinct functions of thymic stromal subsets and age-related changes during thymic involution. Cell reports, 9(1), pp. 402-415.

22. Meredith, M., Zemmour, D., Mathis, D. and Benoist, C., 2015. Aire controls gene expression in the thymic epithelium with ordered stochasticity. Nature immunology, 16(9), p.942. 
23. Rodewald, H.R., Paul, S., Haller, C., Bluethmann, H. and Blum, C., 2001. Thymus medulla consisting of epithelial islets each derived from a single progenitor. Nature, 414(6865), p.763.

24. Derbinski, J., Schulte, A., Kyewski, B. and Klein, L., 2001. Promiscuous gene expression in medullary thymic epithelial cells mirrors the peripheral self. Nature immunology, 2(11), p.1032.

25. Nedjic, J., Aichinger, M., Emmerich, J., Mizushima, N. and Klein, L., 2008. Autophagy in thymic epithelium shapes the T-cell repertoire and is essential for tolerance. Nature, 455(7211), p.396.

26. Takahama, Y., Ohigashi, I., Baik, S. and Anderson, G., 2017. Generation of diversity in thymic epithelial cells. Nature Reviews Immunology, 17(5), p.295.

27. Jakub Abramson, Immunology, Weizmann Institute; PRJNA354356; GEO: GSE89965.

28. Mamoor, S., 2020. Comparative transcriptional profiling of medullary and cortical thymic cell types identifies epigenetic and transcription factors that uniquely define the mTEChi and cTEC lineages.

29. St-Pierre, C., Morgand, E., Benhammadi, M., Rouette, A., Hardy, M.P., Gaboury, L. and Perreault, C., 2017. Immunoproteasomes control the homeostasis of medullary thymic epithelial cells by alleviating proteotoxic stress. Cell reports, 21(9), pp. 2558-2570.

30.Zhao, G.Q. and Hogan, B.L., 1996. Evidence that mouse Bmp8a (Op2) and Bmp8b are duplicated genes that play a role in spermatogenesis and placental development. Mechanisms of development, 57(2), pp.159-168.

31. Ruan, Q.G., Tung, K., Eisenman, D., Setiady, Y., Eckenrode, S., Yi, B., Purohit, S., Zheng, W.P., Zhang, Y., Peltonen, L. and She, J.X., 2007. The autoimmune regulator directly controls the expression of genes critical for thymic epithelial function. The Journal of Immunology, 178(11), pp.7173-7180.

32. Staal, F.J., Meeldijk, J., Moerer, P., Jay, P., van de Weerdt, B.C., Vainio, S., Nolan, G.P. and Clevers, H., 2001. Wnt signaling is required for thymocyte development and activates Tcf-1 mediated transcription. European journal of immunology, 31(1), pp.285-293.

33. Pongracz, J., Hare, K., Harman, B., Anderson, G. and Jenkinson, E.J., 2003. Thymic epithelial cells provide WNT signals to developing thymocytes. European journal of immunology, 33(7), pp.1949-1956. 
34. Mulroy, T., McMahon, J.A., Burakoff, S.J., McMahon, A.P. and Sen, J., 2002. Wnt-1 and Wnt-4 regulate thymic cellularity. European journal of immunology, 32(4), pp. 967-971.

35. Talaber, G., Kvell, K., Varecza, Z., Boldizsar, F., Parnell, S.M., Jenkinson, E.J., Anderson, G., Berki, T. and Pongracz, J.E., 2011. Wnt-4 protects thymic epithelial cells against dexamethasone-induced senescence. Rejuvenation research, 14(3), pp.241-248.

36. Kvell, K., Varecza, Z., Bartis, D., Hesse, S., Parnell, S., Anderson, G., Jenkinson, E.J. and Pongracz, J.E., 2010. Wnt4 and LAP2alpha as pacemakers of thymic epithelial senescence. PloS one, 5(5), p.e10701.

37. Mamoor, S., 2020. The transcriptional landscape of mTEChi and mTEClo.

38. Tomayko, M.M. and Reynolds, C.P., 1989. Determination of subcutaneous tumor size in athymic (nude) mice. Cancer chemotherapy and pharmacology, 24(3), pp. 148-154.

39. Barbee, S.D., Woodward, M.J., Turchinovich, G., Mention, J.J., Lewis, J.M., Boyden, L.M., Lifton, R.P., Tigelaar, R. and Hayday, A.C., 2011. Skint-1 is a highly specific, unique selecting component for epidermal T cells. Proceedings of the National Academy of Sciences, 108(8), pp.3330-3335.

40. Lin, Y., Cui, C., Su, M., Tian, X., Huang, Y., Zhao, J. and Lai, L., 2019. Skint8, a Novel B7 Family-Related Molecule, Negatively Regulates T Cell Responses. The Journal of Immunology, p.ji1800639.

41. Akiyama, T., Shimo, Y., Yanai, H., Qin, J., Ohshima, D., Maruyama, Y., Asaumi, Y., Kitazawa, J., Takayanagi, H., Penninger, J.M. and Matsumoto, M., 2008. The tumor necrosis factor family receptors RANK and CD40 cooperatively establish the thymic medullary microenvironment and self-tolerance. Immunity, 29(3), pp.423-437.

42. Hrycay, E.G. and Bandiera, S.M., 2009. Expression, function and regulation of mouse cytochrome P450 enzymes: comparison with human cytochrome P450 enzymes. Current drug metabolism, 10(10), pp.1151-1183.

43. Pan, Y. and Ong, E.C., 2017. Cytochrome P450 2W1 (CYP2W1)-ready for use as the biomarker and drug target for cancer?. Xenobiotica, 47(10), pp.923-932. 
44. Fei-Lei Chung, F., Wai Mai, C., Yuen Ng, P. and Leong, C.O., 2016. Cytochrome P450 2W1 (CYP2W1) in colorectal cancers. Current cancer drug targets, 16(1), pp. 71-78.

45. Ronchi, C.L., Sbiera, S., Volante, M., Steinhauer, S., Scott-Wild, V., Altieri, B., Kroiss, M., Bala, M., Papotti, M., Deutschbein, T. and Terzolo, M., 2014. CYP2W1 is highly expressed in adrenal glands and is positively associated with the response to mitotane in adrenocortical carcinoma. PloS one, 9(8), p.e105855.

46. Žuklys, S., Handel, A., Zhanybekova, S., Govani, F., Keller, M., Maio, S., Mayer, C.E., Teh, H.Y., Hafen, K., Gallone, G. and Barthlott, T., 2016. Foxn1 regulates in postnatal thymic epithelial cells key target genes essential for $\mathrm{T}$ cell development. Nature Immunology, 17.

47. Kortüm, F., Caputo, V., Bauer, C.K., Stella, L., Ciolfi, A., Alawi, M., Bocchinfuso, G., Flex, E., Paolacci, S., Dentici, M.L. and Grammatico, P., 2015. Mutations in KCNH1 and ATP6V1B2 cause Zimmermann-Laband syndrome. Nature genetics, 47(6), p. 661.

48. Mou, F., Praskova, M., Xia, F., Van Buren, D., Hock, H., Avruch, J. and Zhou, D., 2012. The Mst1 and Mst2 kinases control activation of rho family GTPases and thymic egress of mature thymocytes. Journal of Experimental Medicine, 209(4), pp. 741-759.

49. Velayos-Baeza, A., Vettori, A., Copley, R.R., Dobson-Stone, C. and Monaco, A.P., 2004. Analysis of the human VPS13 gene family. Genomics, 84(3), pp.536-549.

50. Fortier, M.H., Caron, É., Hardy, M.P., Voisin, G., Lemieux, S., Perreault, C. and Thibault, P., 2008. The MHC class I peptide repertoire is molded by the transcriptome. Journal of Experimental Medicine, 205(3), pp.595-610.

51. Yelo, E., Bernardo, M.V., Gimeno, L., Alcaraz-García, M.J., Majado, M.J. and Parrado, A., 2008. Dock10, a novel CZH protein selectively induced by interleukin-4 in human B lymphocytes. Molecular immunology, 45(12), pp.3411-3418.

52. García-Serna, A.M., Alcaraz-García, M.J., Ruiz-Lafuente, N., Sebastián-Ruiz, S., Martínez, C.M., Moya-Quiles, M.R., Minguela, A., García-Alonso, A.M., MartínOrozco, E. and Parrado, A., 2016. Dock10 regulates CD23 expression and sustains B-cell lymphopoiesis in secondary lymphoid tissue. Immunobiology, 221(12), pp. 1343-1350. 
53. Fahl, S.P., Coffey, F., Kain, L., Zarin, P., Dunbrack, R.L., Teyton, L., Zúñiga-Pflücker, J.C., Kappes, D.J. and Wiest, D.L., 2018. Role of a selecting ligand in shaping the murine $\mathrm{\delta}-\mathrm{TCR}$ repertoire. Proceedings of the National Academy of Sciences, 115(8), pp.1889-1894.

54. Gossens, K., Naus, S., Holländer, G.A. and Ziltener, H.J., 2010. Deficiency of the metalloproteinase-disintegrin ADAM8 is associated with thymic hypercellularity. PloS one, 5(9), p.e12766.

55. Kärkkäinen, I., Rybnikova, E., Pelto-Huikko, M. and Huovila, A.P.J., 2000. Metalloprotease-disintegrin (ADAM) genes are widely and differentially expressed in the adult CNS. Molecular and Cellular Neuroscience, 15(6), pp.547-560.

56. Jin, C. and Zhu, M., 2018. RelB intrinsically regulates the development and function of medullary thymic epithelial cells. Science China Life Sciences, 61(9), pp. 1039-1048.

57. Macedo, C., Magalhães, D.A., Tonani, M., Marques, M.C., Junta, C.M. and Passos, G.A., 2008. Genes that code for T cell signaling proteins establish transcriptional regulatory networks during thymus ontogeny. Molecular and cellular biochemistry, 318(1-2), p.63. 
FbxI15

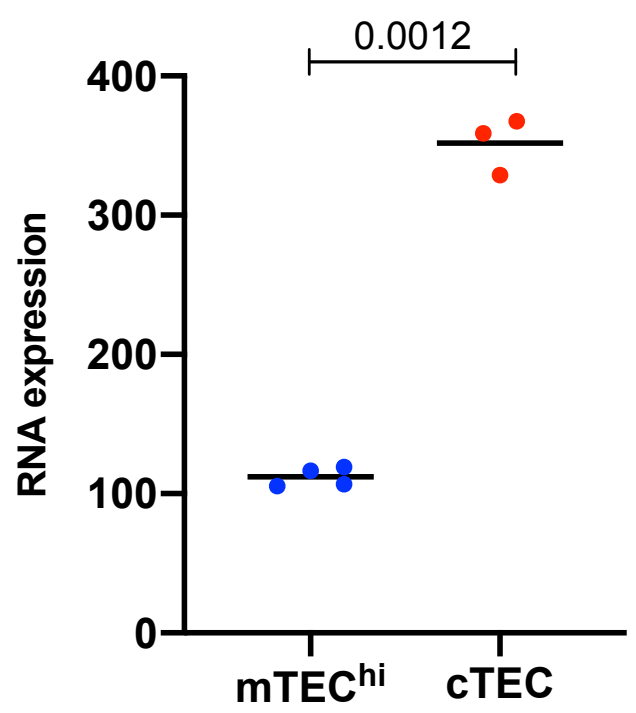

FbxI17

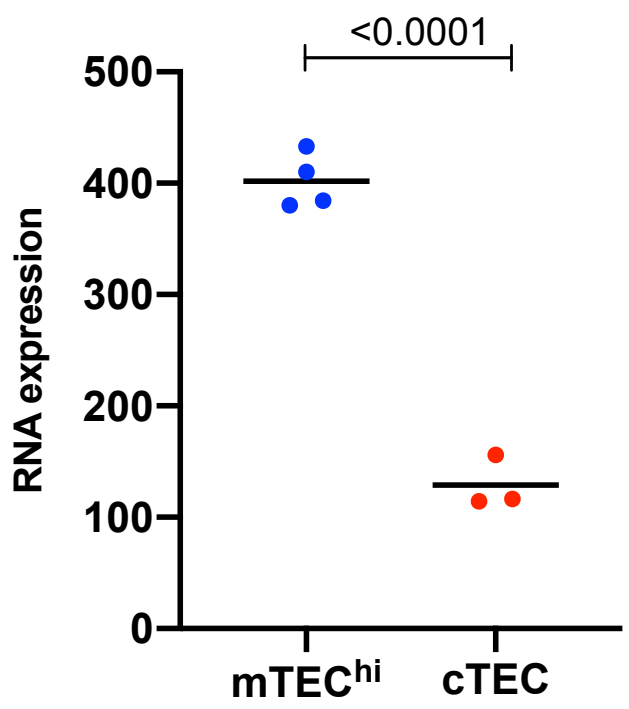

Figure 1: Fbxl15 and Fbxl17 expression uniquely define the mTEChi and cTEC lineages.

The expression of each gene is graphically represented by dots denoting mRA expression level in each cell sample (mTEChi: $n=4$; cTEC: $n=3$ ) with the horizontal black bar representing the mean expression level in each cell type. A statistical test was performed to evaluate the significance of difference between cell type and the result of this test, a $p$-value, is shown on each graph.

Page 22 of 36 


\section{II2rg}

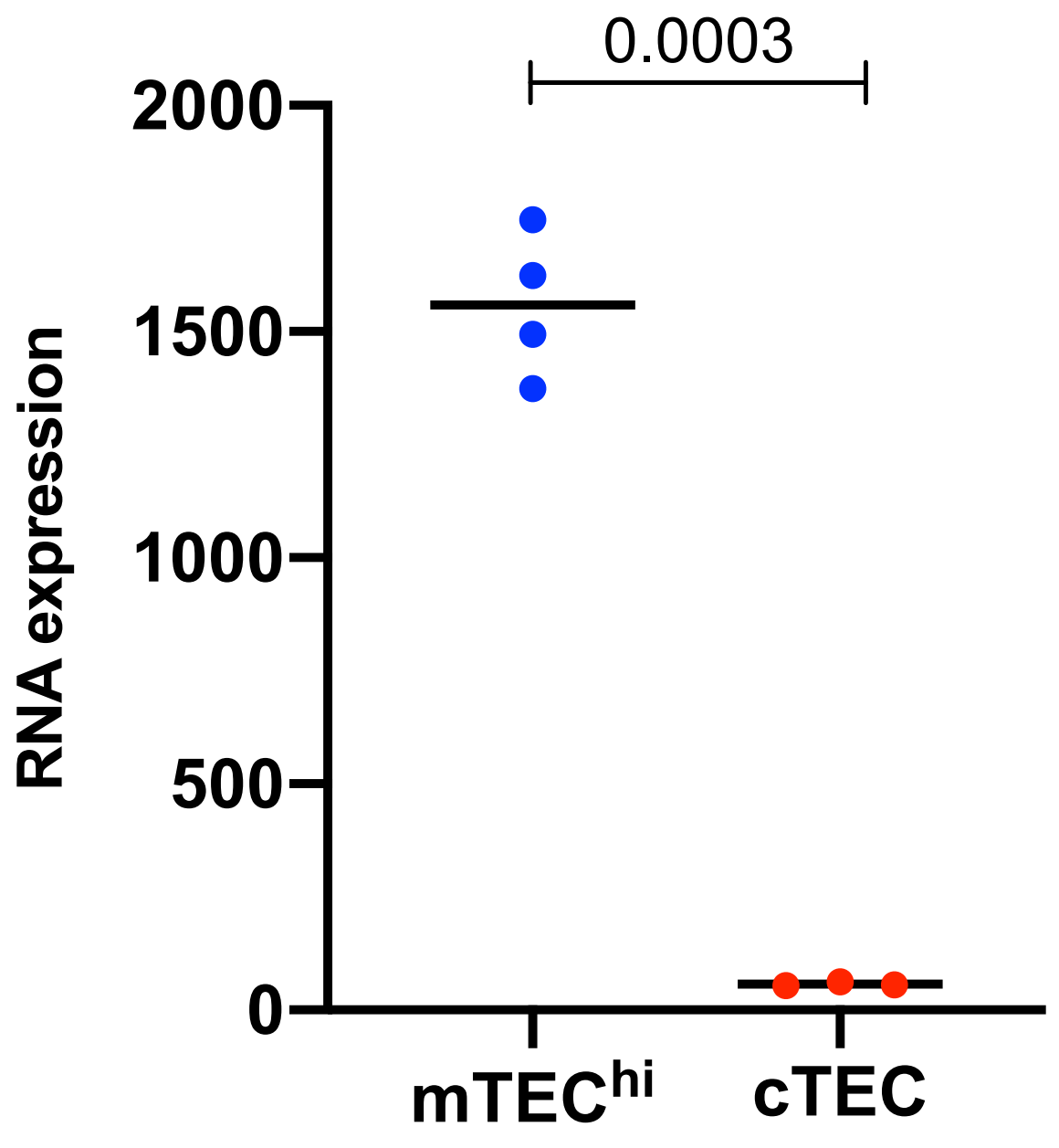

Figure 2: Expression of the gamma chain of the IL-2 receptor uniquely defines the mTEChi lineage from the cTEC lineage.

The expression of II2rg is graphically represented by dots denoting mRNA expression level in each cell sample (mTEChi: $n=4$; cTEC: $n=3$ ) with the horizontal black bar representing the mean expression level in each cell type. A statistical test was performed to evaluate the significance of difference between cell type and the result of this test, a $p$-value, is shown on each graph. 
Scarf2

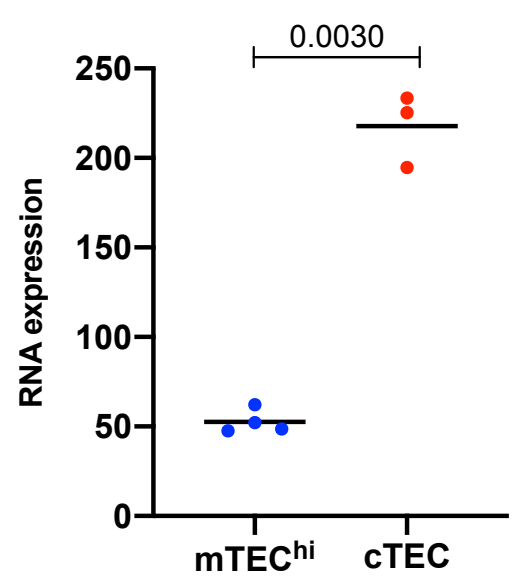

Tnfrsf11a

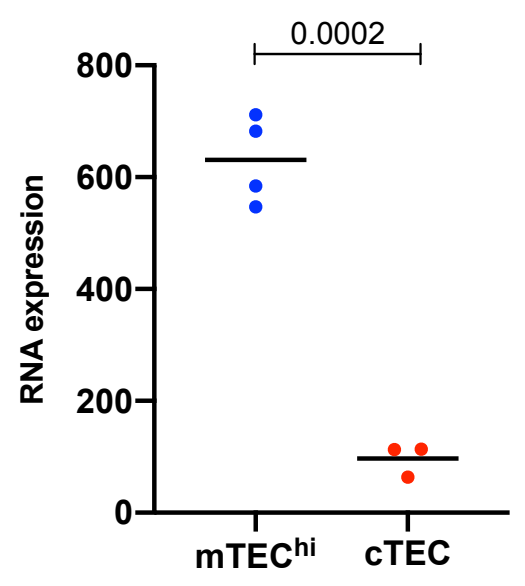

Csf2ra

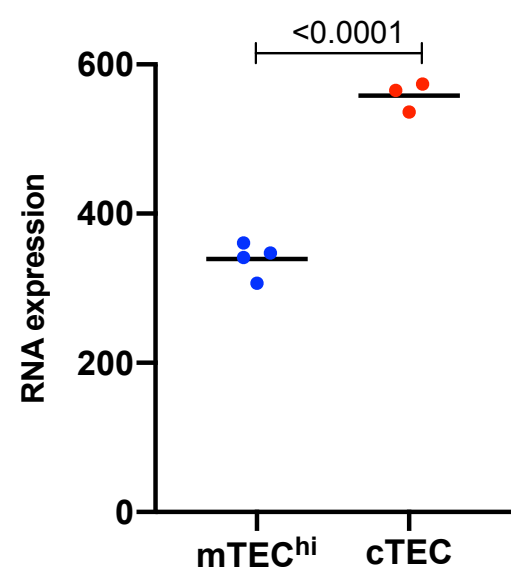

\section{Skint7}

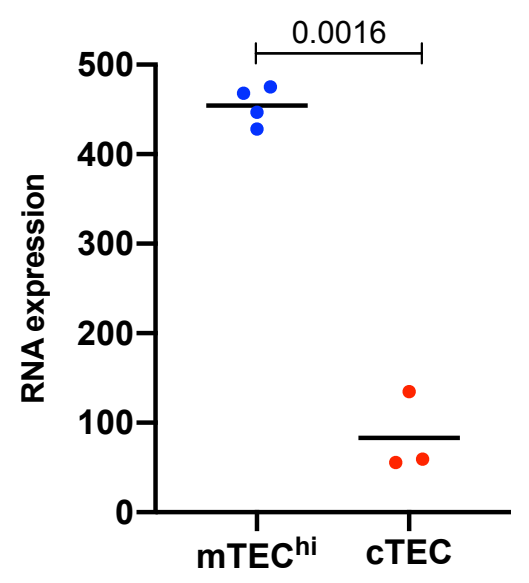

Figure 3: Scarf2, Csf2ra, Tnfrsf11a, Skint7 expression uniquely define the mTEChi and cTEC lineages.

The expression of each gene is graphically represented by dots denoting mRNA expression level in each cell sample (mTEChi: $n=4$; cTEC: $n=3$ ) with the horizontal black bar representing the mean expression level in each cell type. A statistical test was performed to evaluate the significance of difference between cell type and the result of this test, a $p$-value, is shown on each graph. 


\section{Bmp8a}

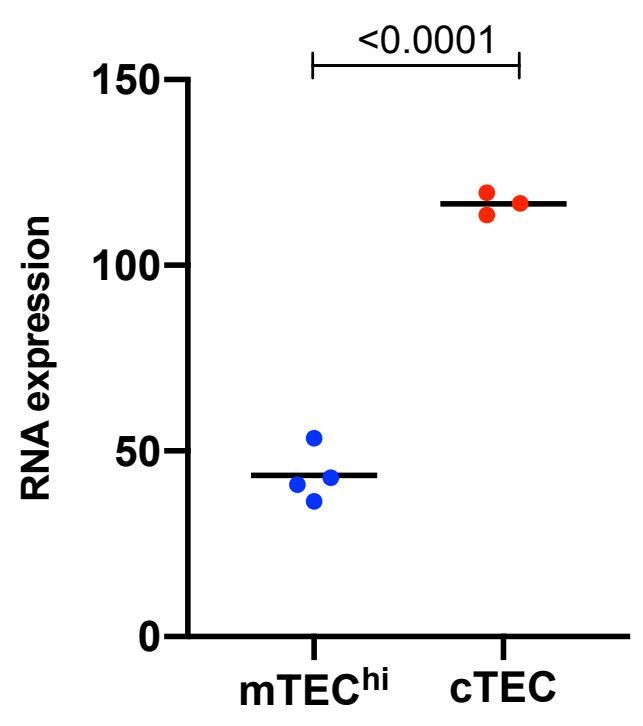

Wnt4

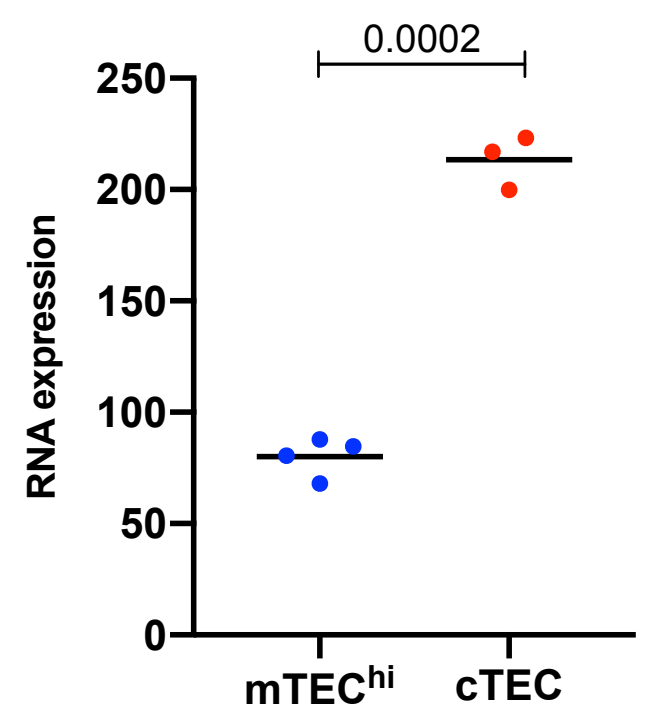

Figure 4: Bmp8a and Wnt4 expression uniquely define the CTEC lineage from the $\mathrm{mTEC}^{\mathrm{hi}}$ lineage.

The expression of each gene is graphically represented by dots denoting mRNA expression level in each cell sample (mTEChi: $n=4$; cTEC: $n=3$ ) with the horizontal black bar representing the mean expression level in each cell type. A statistical test was performed to evaluate the significance of difference between cell type and the result of this test, a $p$-value, is shown on each graph. 

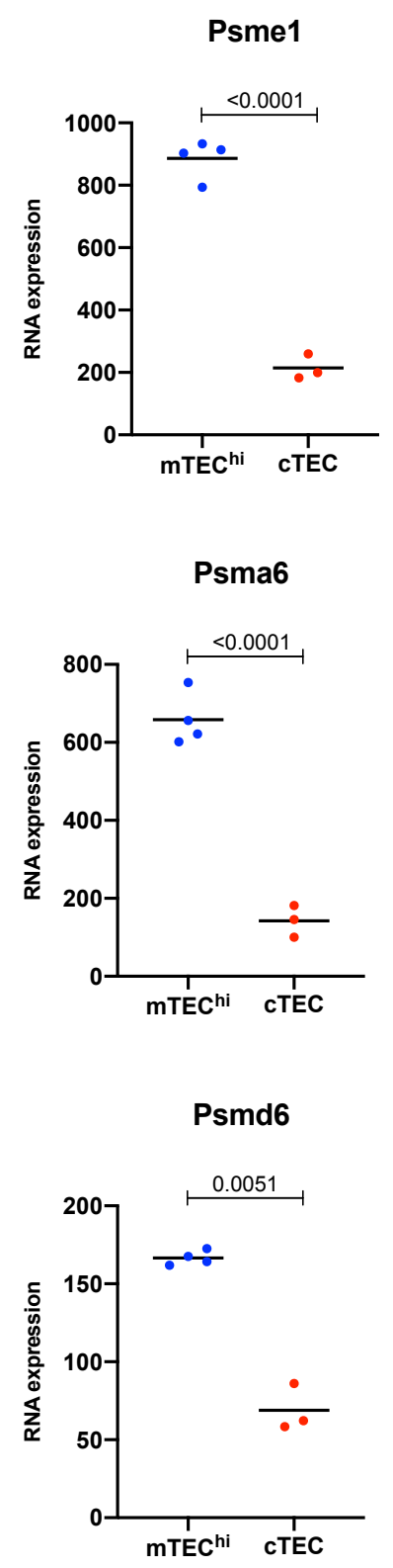

Figure 5: Psme1, Psma6 and Psmd6 expression uniquely define the $m T E C h i$ lineage from the CTEC lineage.

The expression of each gene is graphically represented by dots denoting mRNA expression level in each cell sample (mTEChi: $n=4$; cTEC: $n=3$ ) with the horizontal black bar representing the mean expression level in each cell type. A statistical test was performed to evaluate the significance of difference between cell type and the result of this test, a $p$-value, is shown on each graph. 


\section{Cep350}

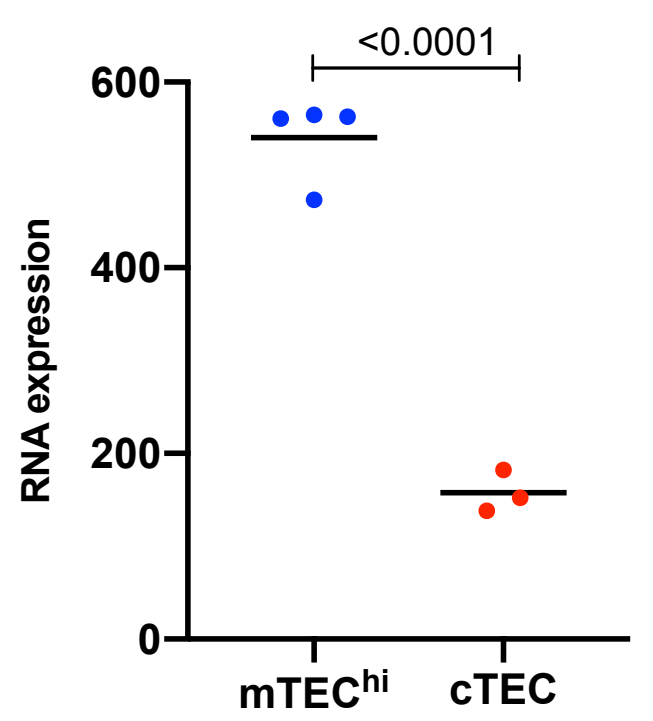

Cep162

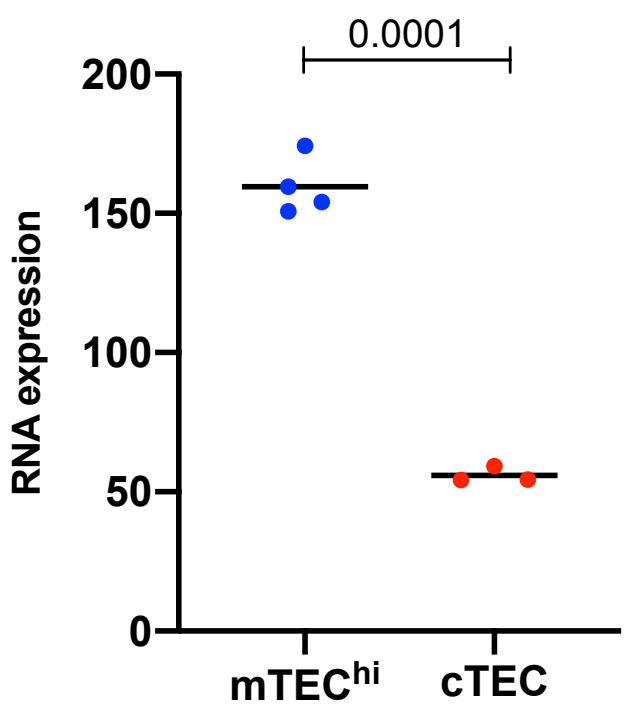

Figure 6: Cep350 and Cep162 expression uniquely define the mTEChi lineage from the cTEC lineage.

The expression of each gene is graphically represented by dots denoting mRNA expression level in each cell sample (mTEChi: $n=4$; cTEC: $n=3$ ) with the horizontal black bar representing the mean expression level in each cell type. A statistical test was performed to evaluate the significance of difference between cell type and the result of this test, a $p$-value, is shown on each graph. 


\section{A (nonagouti)}

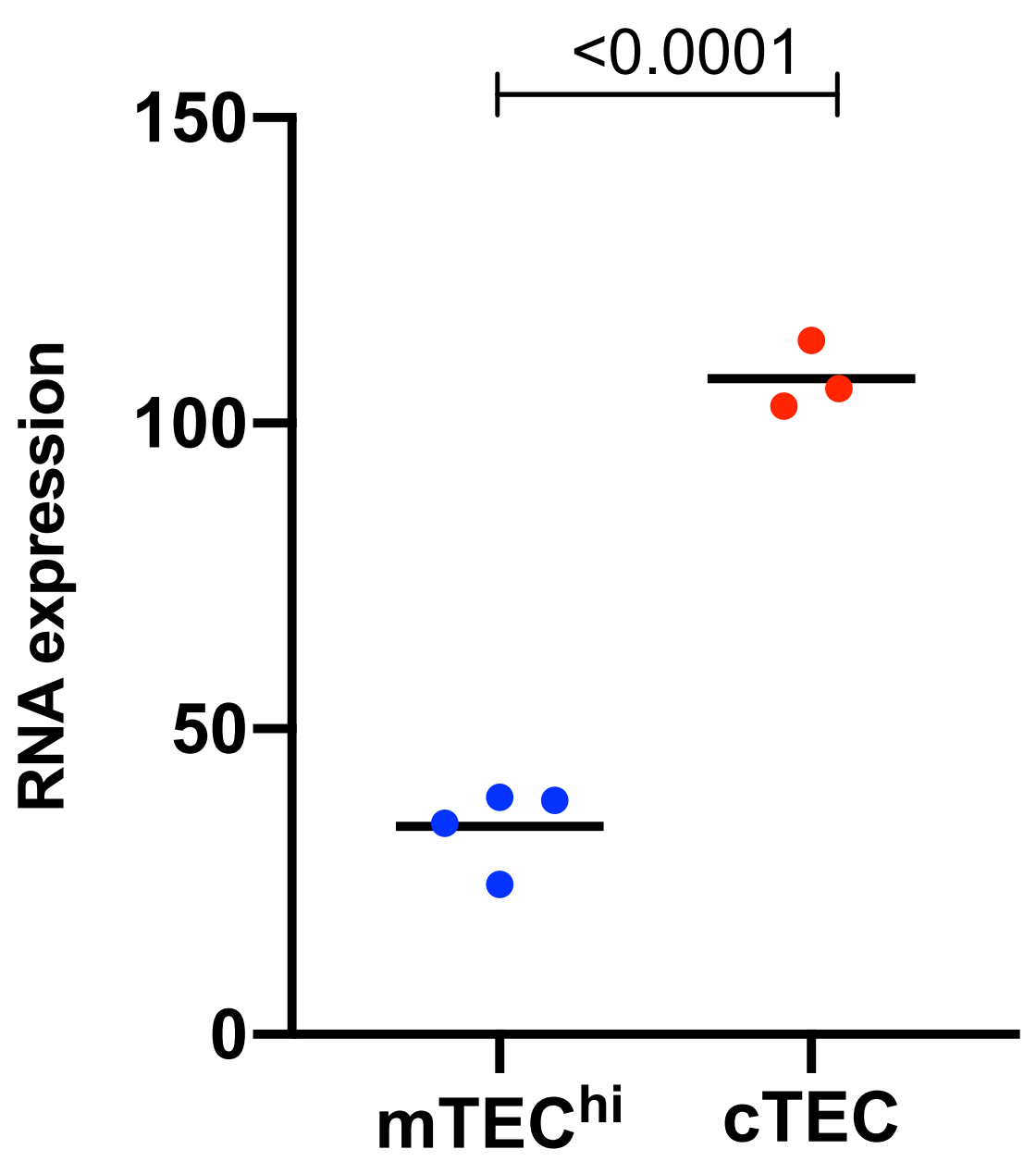

Figure 7: A (Nonagouti) expression uniquely defines the cTEC lineage from the mTEChi lineage.

The expression of each gene is graphically represented by dots denoting mRNA expression level in each cell sample (mTEChi: $n=4$; cTEC: $n=3$ ) with the horizontal black bar representing the mean expression level in each cell type. A statistical test was performed to evaluate the significance of difference between cell type and the result of this test, a $p$-value, is shown on each graph. 

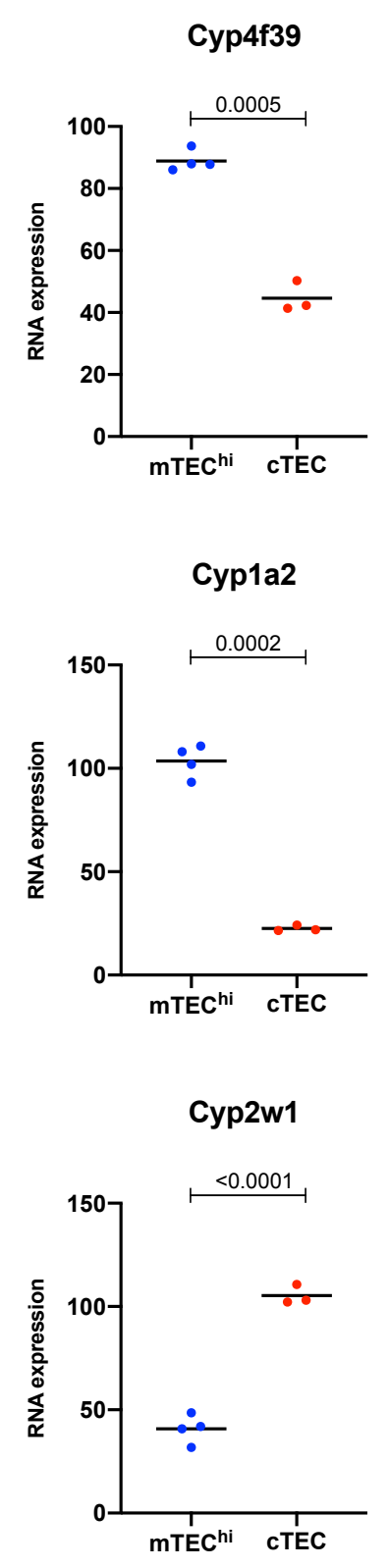

Figure 8: Cyp4f39, Cyp1a2, and Cyp2w1 expression uniquely define the MTEC $^{\text {hi }}$ and CTEC lineages.

The expression of each gene is graphically represented by dots denoting mRNA expression level in each cell sample (mTECh: $n=4$; cTEC: $n=3$ ) with the horizontal black bar representing the mean expression level in each cell type. A statistical test was performed to evaluate the significance of difference between cell type and the result of this test, a $p$-value, is shown on each graph. 

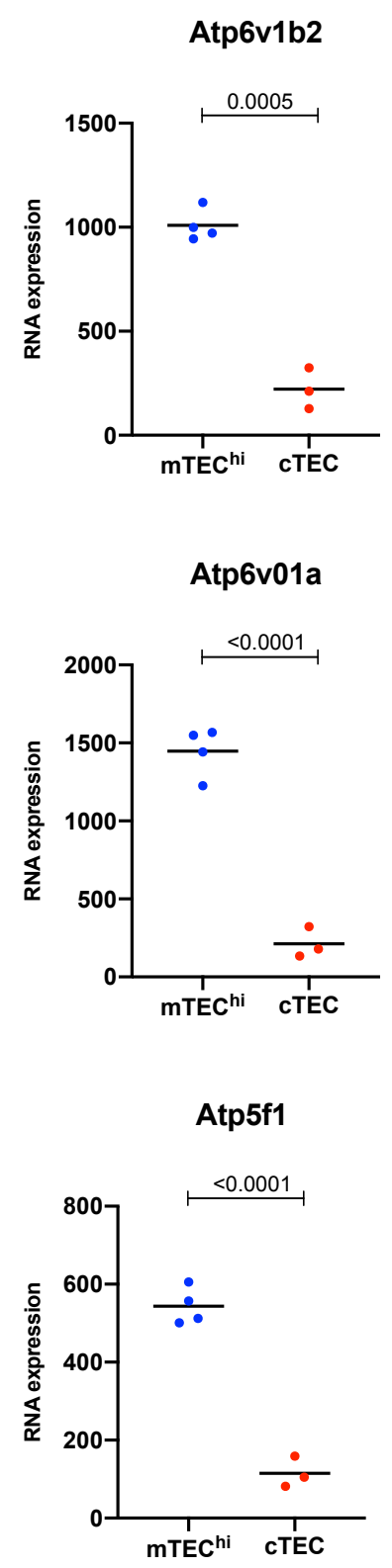

Figure 9: Atp6v1b2, Atp6v01a, and Atp5f1 expression uniquely define the $\mathrm{mTEC}$ hi lineage from the CTEC lineage.

The expression of each gene is graphically represented by dots denoting mRNA expression level in each cell sample (mTEChi: $n=4$; cTEC: $n=3$ ) with the horizontal black bar representing the mean expression level in each cell type. A statistical test was performed to evaluate the significance of difference between cell type and the result of this test, a $p$-value, is shown on each graph. 


\section{Dock6}

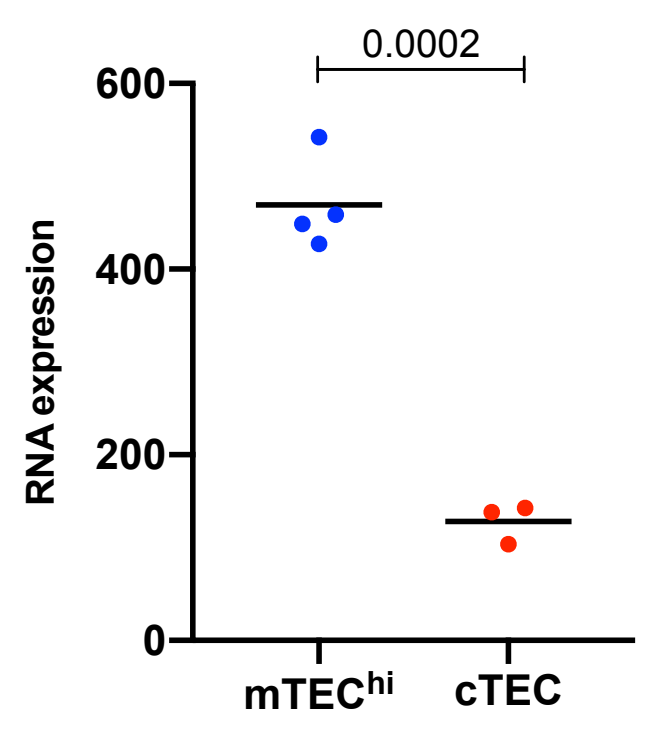

Dock10

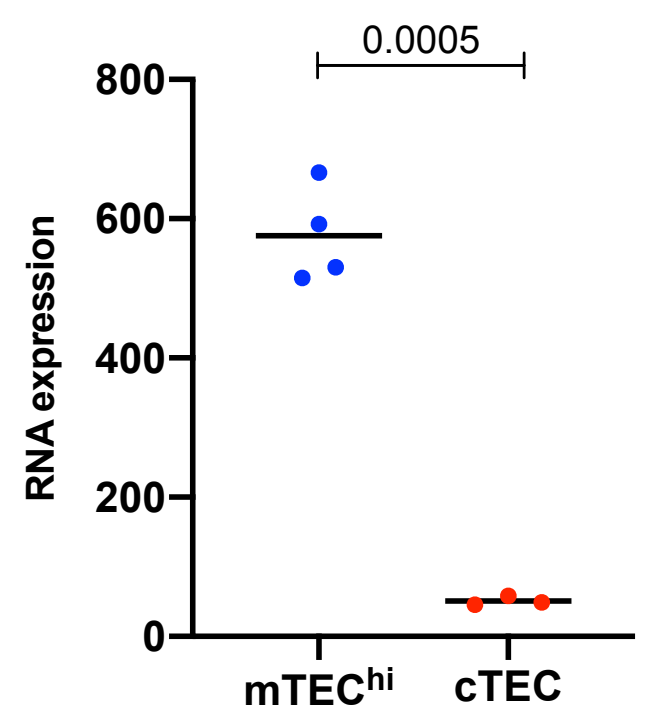

Figure 10: Dock6 and Dock10 expression uniquely define the $m T E C h i$ lineage from the cTEC lineage.

The expression of each gene is graphically represented by dots denoting mRNA expression level in each cell sample (mTEChi: $n=4$; cTEC: $n=3$ ) with the horizontal black bar representing the mean expression level in each cell type. A statistical test was performed to evaluate the significance of difference between cell type and the result of this test, a $p$-value, is shown on each graph. 


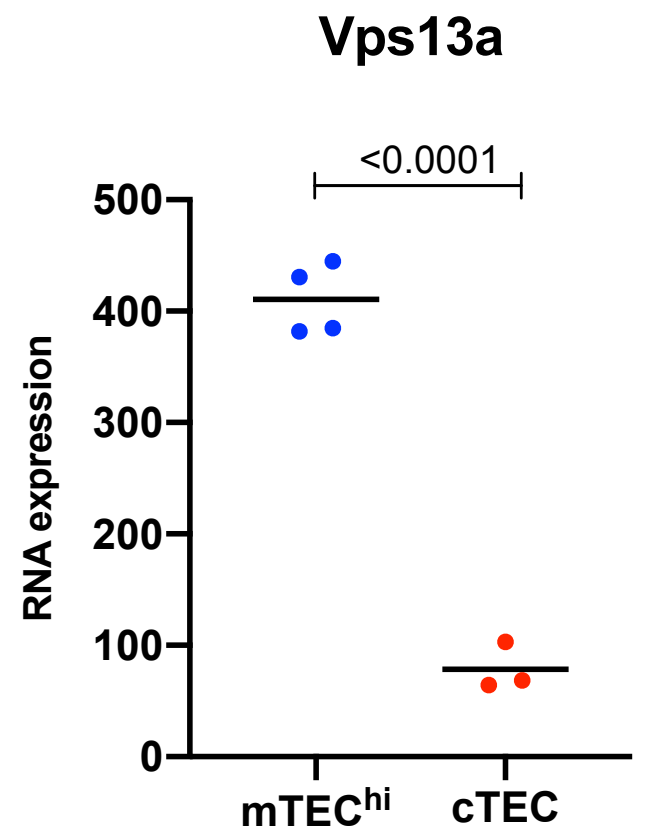

Vps13d

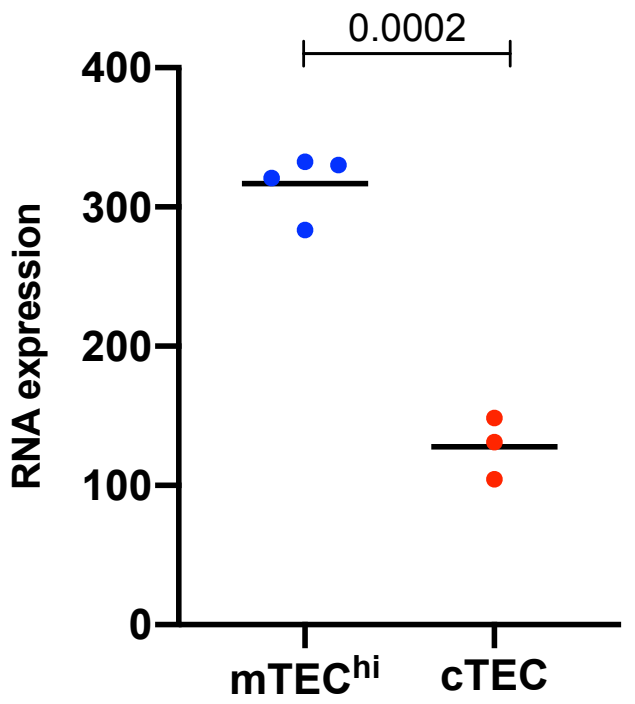

Figure 11: Vps13a and Vps13d expression uniquely define the $\mathrm{mTEChi}$ lineage from the cTEC lineage.

The expression of each gene is graphically represented by dots denoting mRNA expression level in each cell sample (mTEChi: $n=4$; cTEC: $n=3$ ) with the horizontal black bar representing the mean expression level in each cell type. A statistical test was performed to evaluate the significance of difference between cell type and the result of this test, a $p$-value, is shown on each graph. 
H2-Ab1

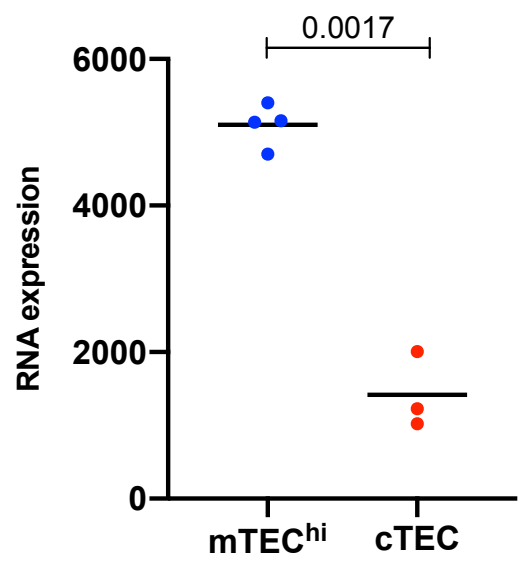

H2-Aa

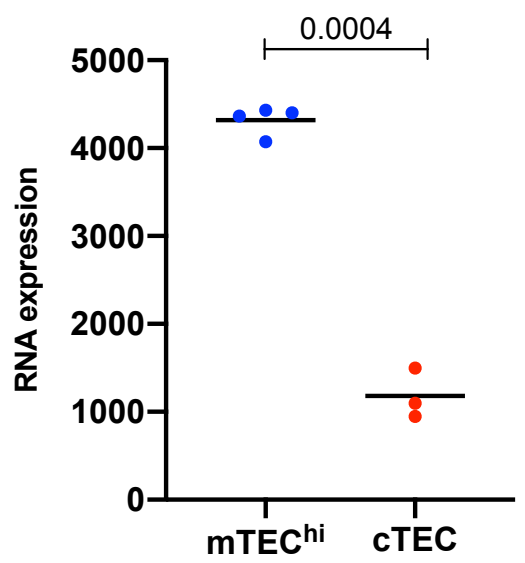

H2-DMb2

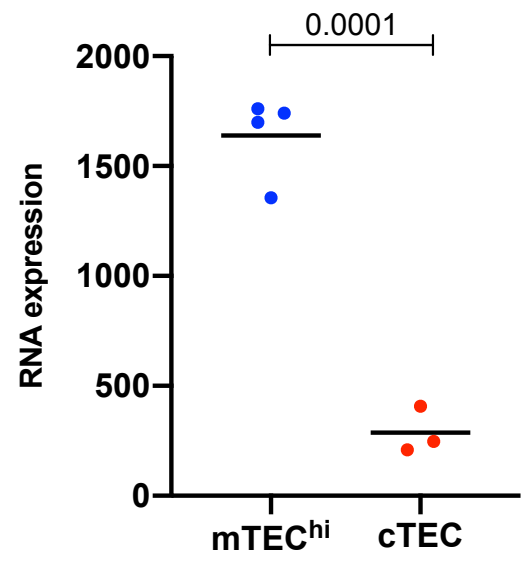

H2-T22

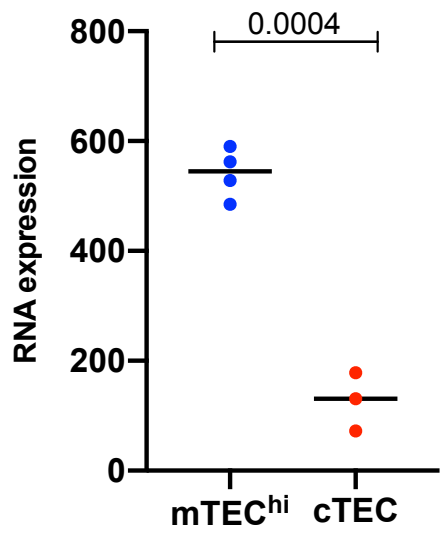

Figure 12: H2-Ab1, H2-DMb2 and H2-Aa expression uniquely define the mTEChi lineage from the cTEC lineage.

The expression of each gene is graphically represented by dots denoting mRNA expression level in each cell sample (mTEChi: $n=4$; cTEC: $n=3$ ) with the horizontal black bar representing the mean expression level in each cell type. A statistical test was performed to evaluate the significance of difference between cell type and the result of this test, a $p$-value, is shown on each graph. 


\section{Adam8}

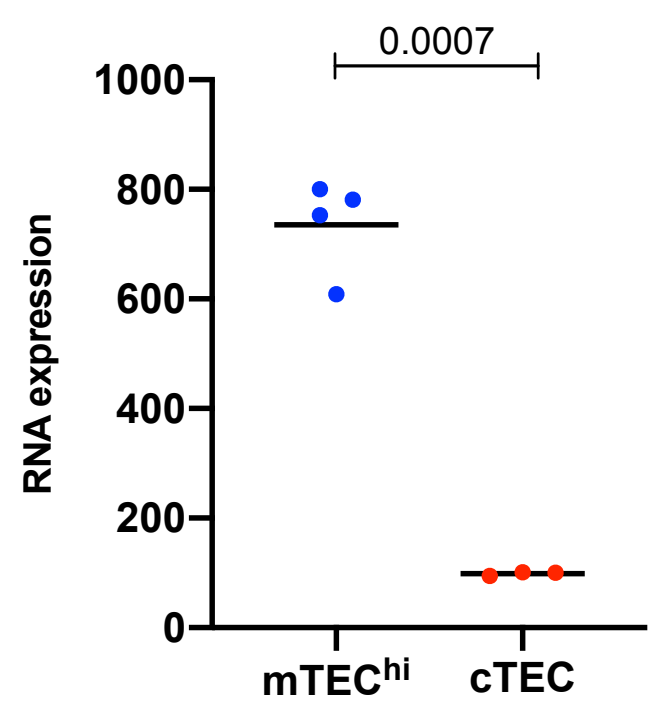

\section{Adam23}

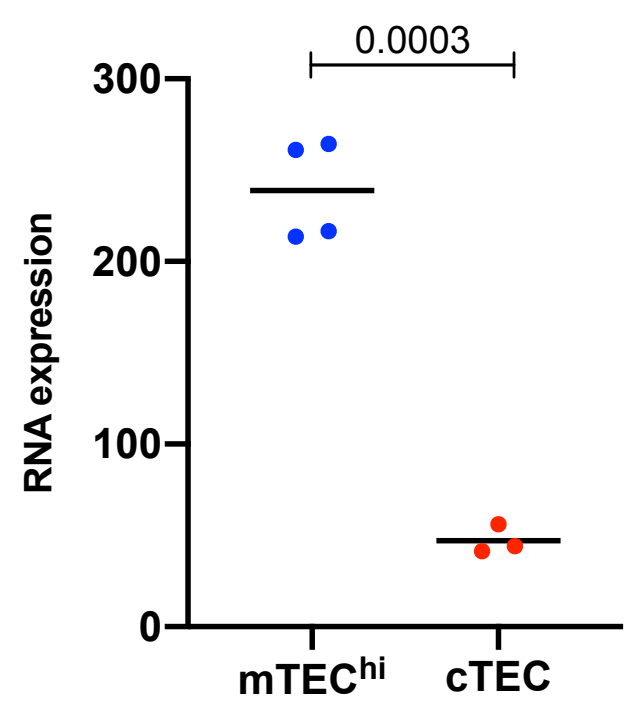

Figure 13: Adam8 and Adam23 expression uniquely define the $\mathrm{mTEChi}$ lineage from the cTEC lineage.

The expression of each gene is graphically represented by dots denoting mRNA expression level in each cell sample (mTEChi: $n=4$; cTEC: $n=3$ ) with the horizontal black bar representing the mean expression level in each cell type. A statistical test was performed to evaluate the significance of difference between cell type and the result of this test, a $p$-value, is shown on each graph. 
Cdca5

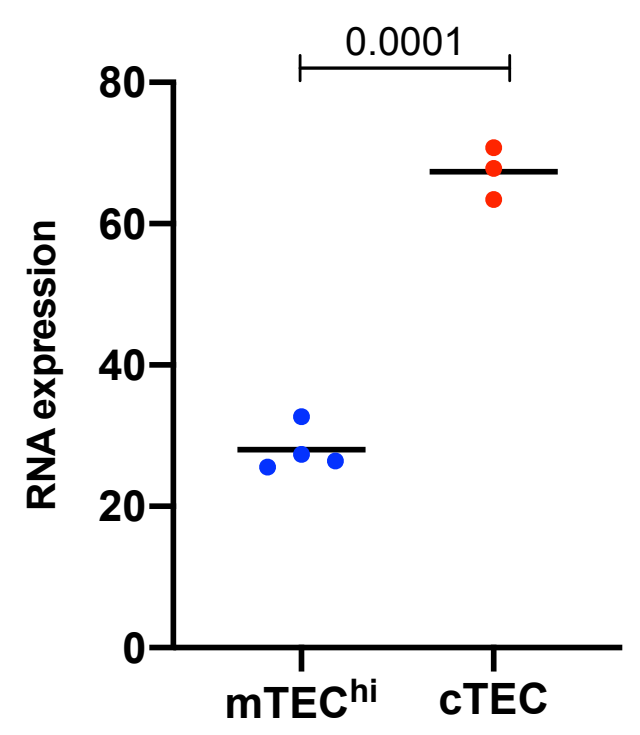

Anapc2

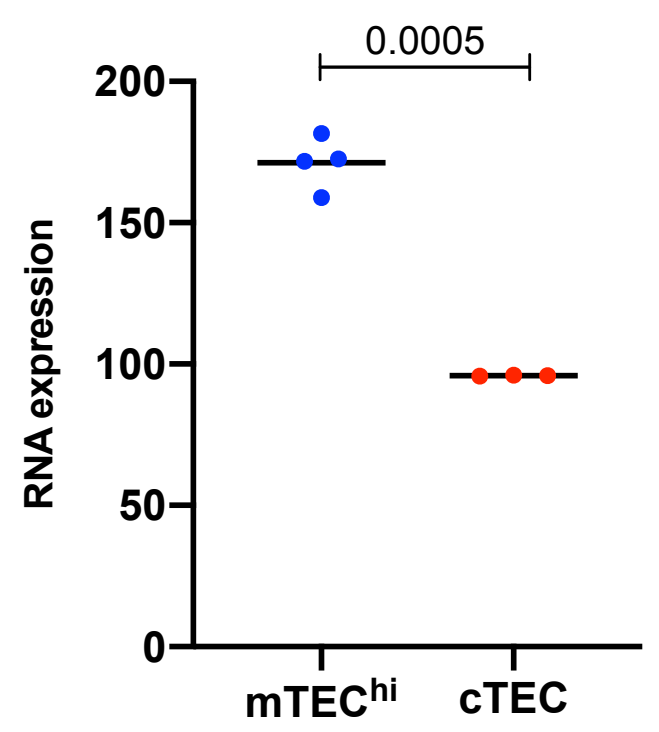

Figure 14: Cdca5 and Anapc2 expression uniquely define the mTEChi lineage and cTEC lineages.

The expression of each gene is graphically represented by dots denoting mRNA expression level in each cell sample (mTEChi: $n=4$; cTEC: $n=3$ ) with the horizontal black bar representing the mean expression level in each cell type. A statistical test was performed to evaluate the significance of difference between cell type and the result of this test, a $p$-value, is shown on each graph. 


\begin{tabular}{|c|c|c|c|c|c|c|}
\hline Rank & Symbol & Gene name & $\mathrm{p}$-value & $t$ & B & ID \\
\hline 9 & Fbxl15 & F-box and leucine-rich repeat protein 15 & $4.9 \mathrm{E}-07$ & 23.8775 & -3.32 & 10463625 \\
\hline 22 & $\mathrm{H} 2-\mathrm{Aa}$ & histocompatibility 2, class II antigen A, alpha & $1.34 \mathrm{E}-06$ & -20.0652 & -3.33 & 10450154 \\
\hline 36 & Wnt4 & wingless-type MMTV integration site family, member 4 & 2.6E-06 & 17.8656 & -3.34 & 10509267 \\
\hline 41 & Psme1 & proteasome (prosome, macropain) activator subunit 1 (PA28 alpha) & $3.21 \mathrm{E}-06$ & -17.2298 & -3.34 & 10415282 \\
\hline 45 & Cyp1a2 & cytochrome P450, family 1 , subfamily a, polypeptide 2 & $3.49 \mathrm{E}-06$ & -16.9802 & -3.34 & 10593981 \\
\hline 46 & $\| 2 \mathrm{rg}$ & interleukin 2 receptor, gamma chain & $3.5 \mathrm{E}-06$ & -16.9718 & -3.34 & 10606016 \\
\hline 48 & Cep162 & centrosomal protein 162 & $3.63 \mathrm{E}-06$ & -16.8583 & -3.34 & 10595529 \\
\hline 52 & Vps13a & vacuolar protein sorting $13 \mathrm{~A}$ & 4.04E-06 & -16.5509 & -3.34 & 10466441 \\
\hline 53 & Scarf2 & scavenger receptor class $F$, member 2 & 4.26E-06 & 16.3977 & -3.34 & 10434105 \\
\hline 60 & Skint7 & selection and upkeep of intraepithelial T cells 7 & 4.99E-06 & -15.9489 & -3.34 & 10507059 \\
\hline 62 & Fbxl17 & F-box and leucine-rich repeat protein 17 & $5.11 \mathrm{E}-06$ & -15.8827 & -3.34 & 10452430 \\
\hline 65 & Bmp8a & bone morphogenetic protein $8 \mathrm{a}$ & $5.29 \mathrm{E}-06$ & 15.7872 & -3.34 & 10516093 \\
\hline 78 & A & nonagouti & $6.53 \mathrm{E}-06$ & 15.2121 & -3.35 & 10477595 \\
\hline 98 & Cep350 & centrosomal protein 350 & 8.91E-06 & -14.4065 & -3.35 & 10359050 \\
\hline 110 & Csf2ra & $\begin{array}{l}\text { colony stimulating factor } 2 \text { receptor, alpha, low-affinity (granulocyte- } \\
\text { macrophage) }\end{array}$ & $1.01 \mathrm{E}-05$ & 14.0961 & -3.35 & 10468893 \\
\hline 121 & Dock10 & dedicator of cytokinesis 10 & $1.11 \mathrm{E}-05$ & -13.8628 & -3.36 & 10356020 \\
\hline 127 & Anapc2 & anaphase promoting complex subunit 2 & $1.18 \mathrm{E}-05$ & -13.7073 & -3.36 & 10469965 \\
\hline 135 & Atp5f1 & ATP synthase, $\mathrm{H}+$ transporting, mitochondrial F0 complex, subunit B1 & $1.27 \mathrm{E}-05$ & -13.5253 & -3.36 & 10386005 \\
\hline 138 & Cyp2w1 & cytochrome P450, family 2, subfamily w, polypeptide 1 & $1.31 \mathrm{E}-05$ & 13.4683 & -3.36 & 10526931 \\
\hline 147 & Adam8 & a disintegrin and metallopeptidase domain 8 & 1.39E-05 & -13.3183 & -3.36 & 10568873 \\
\hline 154 & $\mathrm{H} 2-\mathrm{Ab} 1$ & histocompatibility 2, class II antigen A, beta 1 & $1.54 \mathrm{E}-05$ & -13.0748 & -3.36 & 10444291 \\
\hline 155 & Psmd6 & proteasome (prosome, macropain) 26S subunit, non-ATPase, 6 & $1.55 \mathrm{E}-05$ & -13.0659 & -3.36 & 10417689 \\
\hline 167 & Atp6v1b2 & ATPase, $\mathrm{H}+$ transporting, lysosomal V1 subunit B2 & $1.71 \mathrm{E}-05$ & -12.8356 & -3.37 & 10572146 \\
\hline 169 & Atp6v0a1 & ATPase, $\mathrm{H}+$ transporting, lysosomal V0 subunit A1 & $1.76 \mathrm{E}-05$ & -12.7746 & -3.37 & 10381187 \\
\hline 173 & Сур4f39 & cytochrome P450, family 4, subfamily f, polypeptide 39 & $1.84 \mathrm{E}-05$ & -12.6695 & -3.37 & 10443854 \\
\hline 183 & Cdca5 & cell division cycle associated 5 & $1.98 \mathrm{E}-05$ & 12.5166 & -3.37 & 10460738 \\
\hline 187 & Psma6 & proteasome (prosome, macropain) subunit, alpha type 6 & $2 \mathrm{E}-05$ & -12.4892 & -3.37 & 10395816 \\
\hline 199 & Adam23 & a disintegrin and metallopeptidase domain 23 & $2.25 \mathrm{E}-05$ & -12.2359 & -3.37 & 10346882 \\
\hline 213 & H2-T22 & histocompatibility $2, \mathrm{~T}$ region locus 22 & $2.51 \mathrm{E}-05$ & -11.9966 & -3.37 & 10450694 \\
\hline 224 & Tnfrsf11a & tumor necrosis factor receptor superfamily, member $11 \mathrm{a}, \mathrm{NFKB}$ activator & $2.62 \mathrm{E}-05$ & -11.9075 & -3.38 & 10349051 \\
\hline 232 & Vps13d & vacuolar protein sorting 13D & $2.75 \mathrm{E}-05$ & -11.8045 & -3.38 & 10518228 \\
\hline 234 & $\mathrm{H} 2-\mathrm{DMb} 2$ & histocompatibility 2, class II, locus Mb2 & $2.76 \mathrm{E}-05$ & -11.7949 & -3.38 & 10444236 \\
\hline 246 & Dock6 & dedicator of cytokinesis 6 & $2.98 \mathrm{E}-05$ & -11.6361 & -3.38 & 10591630 \\
\hline
\end{tabular}

Table 1: Comparative transcriptome analysis defines the mTEChi and cTEC lineages. The rank of differential expression, gene symbol and name, $p$-value, $t$ statistic, $B$, the log-odds of differential expression, and the transcript ID (all provided by GEO2R) are shown. 